\title{
Homeroom Teachers or Specialist Teachers?: Considerations for the Workforce for Teaching English as a Subject at Elementary Schools in Japan
}

\begin{tabular}{|l|l|}
\hline Shinji Okumura' & (D) \\
\hline${ }^{1}$ Lecturer, Department of Education, Mukogawa Women's University, Japan & \\
\hline
\end{tabular}

\begin{abstract}
In Japan, English will be officially taught as an academic subject for elementary fifth and sixth graders from 2020. This is a strong initiative of language-in-education policy, aiming at efficient articulation between elementary and junior high schools and targeting the development of English proficiency from early ages simultaneously. However, teacher supply and professional development have been a critical issue for offering English as a subject. Reviewing the recent movement of English education at elementary schools, the paper overviews the current teacher system in public elementary schools in Japan and clarifies that homeroom teachers in Japanese elementary schools tend to work overload not only teaching but also with administrative duties. The paper then describes benefits and drawbacks of homeroom and specialist teachers in English teaching as a subject at elementary schools and argues qualifications of English teachers. The author finally introduces new specialist teacher systems, which will give a useful insight for developing the workforce for the future English education at Japanese public elementary schools.
\end{abstract}

Keywords: English language education reform, Elementary school education, Homeroom teachers, Specialist teachers, Teacher supply, Japan

\section{Contents}

1. Introduction

2. Expansion of English Education in Public Elementary Schools

3. Elementary School Teachers in the Japan Education System

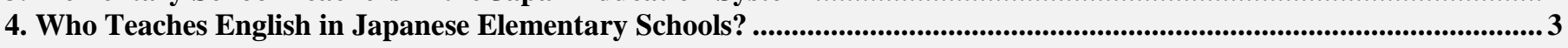

5. New Attempts for Specialist Teacher Systems in Upper Elementary Grades ..................................................................4

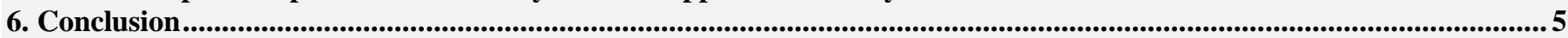

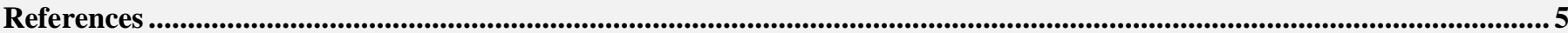

Citation | Shinji Okumura (2017). Homeroom Teachers or Specialist Teachers?: Considerations for the Workforce for Teaching English as a Subject at Elementary Schools in Japan. Asian Journal of Education and Training, 3(1): 1-5.

DOI:

ISSN(E) :

Licensed:

Funding:

Competing Interests:

Transparency:

History:

Ethical:

Publisher: 10.20448/journal.522/2017.3.1/522.1.1.5 Crossref 2519-5387

This work is licensed under a Creative Commons Attribution 3.0 License $(\mathrm{occ}) \mathbf{E}$

This study received no specific financial support.

The author declares that there are no conflicts of interests regarding the publication of this paper.

The authors confirms that the manuscript is an honest, accurate, and transparent account of the study was reported; that no vital features of the study have been omitted; and that any discrepancies from the study as planned have been

Received: 13 December 2016/ Revised: 29 December 2016/ Accepted: 4 January 2017/ Published: 13 January 2017

This study follows all ethical practices during writing.

Asian Online Journal Publishing Group 


\section{Introduction}

Almost three decades ago I was a homeroom teacher at a public elementary school in Tokyo for six years. At that time English was not allocated in the curriculum in public schools, but I tried to offer English lessons during "Special Activity" classes in the curriculum with the permission of the principal as I thought that English would be important for Japanese to live in the future internationalized society. Because I possessed teaching certificates for a secondary English specialist, in addition to that for an elementary generalist, I had some knowledge on teaching English. I firstly enjoyed having English lessons but after a couple of months I began to struggle with planning and conducting lessons because of a lack of resources. As a result, the students were not able to enjoy my lessons. I gradually lacked confidence to teach English even once a week and at the end of the year, I unfortunately felt that I did not want to teach English anymore. From the second year, I invited an English native speaker and mostly depended upon her. I was much relieved and the students enjoyed learning English from her lessons. This is my old story of a former homeroom teacher at a public elementary school in Japan. It is only my experience and cannot be generalized about any homeroom teacher in the recent years.

With the recent acceleration of globalization, the English language has been recognized as an international language throughout the world, and English education has often been required or strongly encouraged in elementary education because an early start is a recent trend in many countries where English is utilized as a second language or learned as a foreign language. Like other countries, in Japan, enriching English education has been one of the recent critical concerns both socially and educationally. Although English education in elementary schools has gradually expanded since the early 2000s, the supply and quality of English teacher have been identified as a significant issue simultaneously. Additionally, a number of elementary school homeroom teachers have been anxious about English education, which will be offered as a subject from 2020. Similarly, there are arguments about who are qualified English teacher in elementary schools. Thus, this paper will argue about workforce for teaching English as a subject at elementary schools with a comprehensive perspective on the Japanese elementary education.

\section{Expansion of English Education in Public Elementary Schools}

From 2002, foreign language education in public elementary schools officially started as a part of education for international understanding. In the class, it is possible for each school to deal with various languages; nonetheless, from the program's beginning the majority of public elementary schools selected English as the target language because of the strong demand of English in the society. In 2011, "Foreign Language Activity" classes have become a compulsory domain for the fifth and sixth graders, which are executed for one hour a week (for 35 unit hours a year). For this class, the Ministry of Education, Culture, Science and Technology (MEXT) of Japan designated that English should be selected in principal. Namely, foreign language education is English education in Japan.

In 2014 MEXT released "English Education Reform Plan corresponding to Globalization" as a language-ineducation policy and started to promote expansion of English education in elementary schools. In this plan, the ministry announced the provision of English language activity classes for third and fourth graders and that of English language subject classes for fifth and six graders (Ministry of Education Culture Science and Technology (MEXT), 2014). This policy initiative will be officially introduced from the implementation of the new Course of Study in 2020.

\section{Elementary School Teachers in the Japan Education System}

Elementary school in Japan is six-year system. Approximately 20,600 schools, including national, public and private sectors exist throughout the country and public schools account for almost 99\% (MEXT, 2016). The number of elementary school teachers is about 420,000 in all sectors (MEXT, 2016). In elementary schools, one class is supervised by one homeroom generalist teacher who is basically responsible for all subjects such as Japanese language, social studies, arithmetic, science and so forth. Conversely, for upper grades, several subjects such as music and home economics are often taught by specialist teachers though the provision of the teachers in school varies in each municipality.

Homeroom teachers are basically in charge of a different grade each year, and therefore, have to develop teaching knowledge and skills for the subjects of all six grades. On the other hand, it is often usual for the teachers to take charge of the same class for two years in a row. In addition to teaching, homeroom teachers have to supervise the students' activities during recesses and lunchtime, and they also have responsibilities for doing some school administrative work, and interviewing parents if necessary. Specialist teachers basically teach their subjects for given classes and they also have to have some school administrative duties together with homeroom teachers.

In fact, Japanese teachers need to spend a lot of time managing administrative work such as participating in various staff meetings and providing a number of administrative documents. Moreover, teachers have several duties outside the school in order to cooperate with other schools and teachers in their municipalities. MEXT (2015) reported that teachers have recently felt overloaded because time for administrative duties has increased and teachers' overtime enlarged simultaneously. Comparing teachers' work environment of other countries, time spent by teachers in Japan for their administrative duties, averagely totaling 5.5 hours per week, is longer than that of 2.9 hours in the OECD countries.

In the recent educational environment around Japanese teachers, contents of teaching subjects have been diversified and advanced. For instance, the use of information communication technology (ICT) is currently promoted in education, and thus, homeroom teachers need to equip ICT knowledge and skills in association with teaching various subjects. Similarly, teaching English as a subject obviously involves advanced elements such as enhancing students' English skills and assessing their attainment. In addition, MEXT (2014) encourages public elementary school teachers to maximize the connection between ICT and English in order to enhance students' motivation, engagement and English skills. Thus, elementary school teachers need to equip knowledge and skills in both ICT and English synchronously. 


\section{Who Teaches English in Japanese Elementary Schools? \\ 4.1. Current Situation}

The "Foreign Language Activity" classes are basically conducted by homeroom teachers in the current education system. However, many of Japanese homeroom teachers' qualification for teaching English is not adequate enough. According to MEXT (2015) only 4.9 percent of elementary school teachers possess a teacher's certificate of English and only $2.7 \%$ have Grade Pre-1 in the EIKEN Test in Practical English Proficiency (TOFEL iBT80 or TOEIC730 equivalent). Moreover, many elementary school teachers, especially those who are middle-aged, did not learn how to teach English in pre-service teacher education since college classes concerning teaching English in elementary school were not required to obtain teaching licenses a few decades ago.

Assistant Language Teachers (ALTs) from overseas often help homeroom teachers in English classes. MEXT (2015) revealed that the use of ALTs have increased and 60\% of public elementary schools use them in 2014. Conversely, supply and use of ALTs vary in each municipal district or individual school (MEXT, 2014). Furthermore, Japanese Language Teachers (JTEs) as specialist teachers or assistants are appointed in some public schools but overall they are not many yet (Eiken Foundation of Japan, 2013).

In the current situation related to the workforce for teaching English in public elementary schools, many inservice homeroom teachers have been anxious about teaching English due to a lack of English ability, adequate English teaching skills (Okumura, 2010; Yoshida, 2015). In fact, a recent survey (EFJ, 2013) acknowledged that English teaching skills and methods are significant concerns for in-service elementary school teachers. Considering this fact, MEXT (2014) clarifies that a high-level of English proficiency and teaching skills should be acquired by elementary school teachers for the future expansion of English education in elementary schools. Moreover, in the recent teacher employment process, a number of municipal boards of education offer written examinations or practical skill tests in order to supply homeroom teachers who can teach English in elementary schools (MEXT, 2016).

\subsection{Benefits and Drawbacks of Homeroom and Specialist Teachers}

It is currently controversial who should teach English as a subject in elementary schools. MEXT (2006a) designates benefits and drawbacks of homeroom and specialist teachers in terms of teaching English at elementary schools (see Table 1). Nevertheless, some of the benefits and drawbacks are debatable for teaching English as a subject in the near future. Firstly, it is arguable that homeroom teachers are appropriate to connect teaching English with other subjects but specialist teachers are not. In reality, it is obvious that homeroom teachers possess knowledge of different subjects, and recently several teachers who take charge of "Foreign Language Activity" classes actively incorporate content-based approaches such as Content and Language Integrated Learning (CLIL). CLIL, which explores the integration of teaching curricula content and second or foreign languages, has been the recent trend in foreign or second language education throughout the world. However, content-based approaches are not easy to be incorporated into foreign language curricula because they basically aim at developing foreign or second language skills and acquiring knowledge of academic contents in a balanced way. More specifically, although CLIL has recently highlighted in any level of English education in Japan including the elementary level, there is a danger that any type of content-based lessons is referred to CLIL superficially. CLIL has one important pedagogic concept, which is known as the 4Cs Framework (Coyle, 2006). The 4 Cs Framework is a holistic approach and includes content (subject matter), communication (language learning and using), cognition (learning and thinking processes), and culture (developing intercultural understanding and global citizen-ship), in order to construct the collaborations of integrating learning in other curriculum areas (content and cognition) and language learning (communication and cultures).

As mentioned above, considering that many Japanese teachers work overloaded not only in teaching but also with administrative work, it is doubtful that homeroom teachers who take charge of English instructions can provide effective content-based English lessons since they require various resources which integrate English into academic contents. Moreover, it is necessary for homeroom teachers to be provided in-service training for content-based approaches so as to understand them precisely, receiving the training for general English teaching methods and English language skills in parallel. Though MEXT shows that specialist teachers have difficulty in using contentbased approaches, possibly because they are not generalist teachers. Nonetheless, it is not doubtful that specialist teachers have a certain degree of knowledge in academic subjects at the elementary level. Even specialist teachers will be able to apply their prior knowledge to English lessons. More importantly, as MEXT proposed, specialist teachers can focus on teaching English, and hence, they can actively participate in professional development opportunities for content-based approaches in order to develop the knowledge and skill.

In order to develop homeroom teachers' English teaching skills, governments and non-governmental teachers' associations have promoted professional development for teaching English in elementary schools. Although professional learning opportunities increase, it is unrealistic that all homeroom teachers would be able to acquire high levels of English proficiency and adequate English teaching skill because of their aptitude for English language. Correspondingly, homeroom teachers' attitudes towards English education are different individually since each homeroom teacher's specialization or strength varies. Therefore, in-service teacher training for homeroom teachers are not always effective and omnipotent. A teacher's passion cannot simply be enhanced by in-service teacher training. Some teachers could have confidence but others might have a sense of inferiority after the training because of a lack of English knowledge and proficiency.

Second, it is clear that homeroom teachers have a close psychological distance to their students, and it is also easy for the teachers to control their classrooms. Conversely, in the current Japanese education system, Music, Art or home economics is taught by specialist teachers in a great number of public elementary schools throughout the country and significant problems have not been identified. The critical question here is why English should be special? Even if specialist teachers have a psychological distance to the students, the essential point is the importance 
of sharing information of students with homeroom teachers to solve students' issues, cooperating with each other. Similarly, whole school involvement is noteworthy, so that specialist teachers are not peripheral or isolated in school.

Table-1. Benefits and drawbacks of homeroom and specialist teachers

\begin{tabular}{l|ll|l}
\hline & Homeroom teachers & Specialist teachers \\
\hline Benefits & $\begin{array}{l}\text { As homeroom teachers teach different subjects } \\
\text { such as Japanese and social studies, it is } \\
\text { appropriate to connect English teaching with } \\
\text { other subjects. }\end{array}$ & $\begin{array}{l}\text { Specialist teachers are in general expected } \\
\text { to have higher English proficiency and } \\
\text { teaching skills than homeroom teachers. } \\
\text { Homeroom teachers can utilize prior } \\
\text { experiences of "Foreign Language Activity" } \\
\text { classes. }\end{array}$ & $\begin{array}{l}\text { Specialist teachers possess expertise in } \\
\text { terms of planning lessons and selecting } \\
\text { materials and they can enrich teaching } \\
\text { contents. }\end{array}$ \\
$\begin{array}{l}\text { Homeroom teachers understand characteristics } \\
\text { of students more than specialist teachers as they } \\
\text { have a close psychological distance to the } \\
\text { students. }\end{array}$ & $\begin{array}{l}\text { Specialist teachers can focus on teaching } \\
\text { English. They can actively participate in } \\
\text { training opportunities and develop teaching } \\
\text { skills effectively. }\end{array}$ \\
\hline Drawbacks large number of teachers need to receive in- \\
$\begin{array}{l}\text { service teacher training, especially in developing } \\
\text { English proficiency and teaching skills. }\end{array}$ & $\begin{array}{l}\text { It is difficult to connect English teaching } \\
\text { with other subjects such as Japanese and } \\
\text { social studies. }\end{array}$ \\
\hline *The original of this table is written in Japanese (MEXT, 2006a) and the author extracted the corresponded part and translated Japanese into English.
\end{tabular}

\subsection{Who is a Qualified Teacher of Teaching English as a Subject?}

Who should teach English as a subject in public elementary schools has been debated by a number of researchers, English language advocates and in-service teachers. Their opinions are divided into two, namely homeroom and specialist teachers. In discussing conditions of qualified teachers for English as a subject in elementary school, it is important to recognize that English as a subject is different from "Foreign Language Activity" classes mainly because the main aim of the subject is to develop students' English competency. Yoshida (2015) assert that it is necessary to supply specialists who can teach English more systematically for a subject. In fact, teachers who teach English at elementary schools have to teach pronunciation, vocabulary, listening and speaking, and moreover, reading and writing a new alphabet, and easy words have to be taught for the subject. These teaching elements have to be taught correctly since they will become the base of English learning in junior high schools. Moreover, teachers need to assess students' achievement comprehensively and validly. Thus, teachers who teach English as a subject have to possess a wide range of knowledge on applied linguistics including foreign language teaching and learning.

Additionally, it is necessary for the teachers to help students feel secure in English lessons. Scott and Ytreberg (1990) state that security is vital to maximize the outcome of students' language learning. Consequently, skills which enable students to feel secure in the lessons are essential for qualified English language teachers. Similarly, it is critical not only for students but also for teachers to have confidence to use English for students (Butler, 2015).

Unless teachers can teach English confidently, they cannot allow students to feel secure in their English instruction. Similarly, motivation and enthusiasm for teaching foreign language is necessary for English language teachers. Unless teachers have passion for teaching English, they will not able to provide attractive lessons. Understanding of the Japanese elementary school system and the associated educational culture is also essential.

In this way, qualified teachers for English as a subject in elementary schools should possess varied knowledge, skills and enthusiasm. The question to be considered here is whether homeroom teachers are absolutely suitable to teach English as a subject, always having passion for it. Considering homeroom teachers' work environment in the current Japanese education system noted above, it is reasonable that teaching English as a subject will be a burden on a number of homeroom teachers who are not qualified as English teachers. In my opinion, specialist teachers systems should be enhanced for teaching English as a subject.

\section{New Attempts for Specialist Teacher Systems in Upper Elementary Grades}

Importance of the articulation between elementary and junior high schools has been newly highlighted mainly because of new perspectives on children's cognitive and physical development. For instance, Abiko (2007) claims that many upper elementary school children are reaching adolescence earlier than before, and the current 6-3-3 education system cause problems due to critical gaps between elementary and junior high school education. Under such a situation, MEXT proposed the necessity of argument about a specialist teacher system for upper graders in elementary schools (MEXT, 2006b).

Considering issues of the transition between elementary and junior high schools, several municipal boards of education have attempted new specialist teacher systems for upper graders in elementary school. For example, Hyogo prefecture has conducted a sustainable case study on a specialist teacher system for elementary schools since 2009 (Hyogo Prefectural Board of Education, 2011). Although selection of specialist subjects are based upon each case study school's decision, many of them incorporated the system for arithmetic, science, music, art, home economic. Some schools use the system for "Foreign Language Activity" classes. Similarly, in Iwate prefecture one public elementary school attempted a specialist teacher system from 2011 to 2013. Iwate Prefectural Board of Education (2014) reported that the school selected arithmetic, science, music, and handwriting because of requirement of specific knowledge and skills, necessity of a large amount of preparation time and possibility of adopting various learning styles including team-teaching. The significant positive aspects which were common in the two attempts included that teachers were able to develop lessons teach them effectively, and that many students thought that lessons which are understandable increased. Psychological distance to the students was not an issue in the two trials, but understanding students was facilitated based upon teachers' interaction and collaboration. On the other hand, time constraints due to school events such as sports day and school excursions were identified as an 
administrative issue. It will be useful to consider the specialist teacher system for upper graders in public elementary school for teaching English as a subject, in order to provide well-organized English instructions.

\section{Conclusion}

For English education as a compulsory subject from 2020, it is significant to consider who will take charge of the lessons. The main argument of this paper is: who is a qualified teacher for English instruction as a subject in elementary classrooms, considering the current work environment in Japanese public elementary schools? Whereas I recognize that homeroom teachers play important roles in elementary education, in my opinion, it is difficult for them to have huge responsibilities for teaching English as a subject mainly because of their business for various administrative duties in addition to teaching. Overlooking the current elementary education in Japan must be necessary to consider the workforce of elementary English education for development of foreign language-ineducation. Correspondingly, it is important for English language advocates to not only focus on English education but also to understand homeroom teachers comprehensively. It is essential to acknowledge that homeroom teachers are generalists but they are not always almighty. Moreover, as more teaching contents become advanced and complicated in the future elementary education, the more teachers have to specialize in specific subjects, especially in upper elementary grades. As introduced in this paper, specialist teacher system for upper graders should be appreciated if schools have a plan to enable students to acquire basic knowledge of academic contents. Specifically, in elementary English education as a subject, it should be highlighted that English language must be taught comprehensively and correctly, so that elementary English can allow students to develop their English competency sustainably.

\section{References}

Abiko, T., 2007. Kodomo no souki seijyukuka ni taiousita gakkoo taikei wo [School System Dealing with Children's Early Maturation]. BERD, 07: 8-13. Retrieved from http://berd.benesse.jp/berd/center/open/berd/2007/01/pdf/07berd_02.pdf.

Butler, Y.G., 2015. Shoogakko eigo kyokaka-no arikata [Concerning English Education at Elementary School as an Academic Subject]. Kyoiku-to Igaku. Education and Medicine, 63(12): 20-27.

Coyle, D., 2006. Developing CLIL: Towards a theory of practice. Monograph 6. Barcelona: APAC.

Eiken Foundation of Japan, 2013. Shoogakko no gaikokugo katsudo oyobi eigo katsudo tou ni kansuru genjyothosa [Survey of Current Situations Concerning Foreign Language Activities and English Activities]. Retrieved from https://www.eiken.or.jp/center_for_research/pdf/market/elementary_press_2712.pdf.

Hyogo Prefectural Board of Education, 2011. Shogakko ni okeru aratana shidou shisutem "Hyogo-gata kyouka tannisei" [A New Instruction System in Elementary Schools: 'Hyogo Specialist Teacher System']. Retrieved from www.hyogo-c.ed.jp/ gimubo/rennkei/H22hyogogata.pdf.

Iwate Prefectural Board of Education, 2014. Syogakko koogakunen ni okeru kyooka tanninsei no dounyuu nitsuite [Introduction of Specialist Teacher Systems for Upper Grade Elementary Level]. Retrieved from www1.iwate-ed.jp/db/db2/sid_data/ather/kyokatanninsei.pdf.

MEXT, 2006a. Shogakko noeigo kyouiku ni okeru gakkyuu tannin tosennkakyouin no tokutyoo rei [Examples of characteristics of Homeroom Teachers and Specialist Teachers in English Education at Elementary Schools]. Retrieved from http://www.mext.go.jp/bmenu/shingi/chukyo/chukyo3/siryo/015/06020613/006.htm.

MEXT, 2006b. Kyoikukatei bukai "Shingi keika houkoku” (Heisei 18nen 2gatsu 13nichi). [Curriculum Sub-Committee 'The Progress Report' (2006/02/13)]. Retrieved from http://www.mext.go.jp/b_menu/shingi/chukyo/chukyo3/siryo/07061432/003.htm.

MEXT, 2015. Gakko ya kyoshokuin no genjyo ni tsusite. [About the Current Situation of Schools and the Faculty]. Retrieved from http://www.mext.go.jp/b_menu/shingi/chukyo/chukyo3/052/siryo/_icsFiles/afieldfile/2015/02/18/1355024_4.pdf.

MEXT, 2016. Statistical abstract 2016 edition. Retrieved from http://www.mext.go.jp/en/publication/statistics/title02/detail02/1379369.htm.

Ministry of Education Culture Science and Technology (MEXT), 2014. English education reform plan corresponding to globalization. Retrieved from http://www.mext.go.jp/en/news/topics/detail/1372656.htm.

Okumura, S., 2010. Foreign language activities and foreign language. In Y. Murata \& M. Yamaguchi (eds.) Education in Contemporary Japan -System and Content. Tokyo: Toshindo.

Scott, W.A. and L.H. Ytreberg, 1990. Teaching english to children. England: Pearson Education.

Yoshida, K., 2015. Shoogakko no eigo ha nani wo dou oshierubekika. [What and how should be Taught in English Education at Elementary School ]. Kyoiku-to Igaku. Education and Medicine, 63(12): 4-11. 